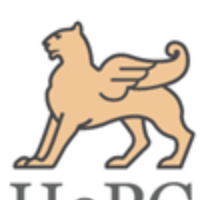

$\mathrm{HePG}$

ISSN: 2348-1900

Plant Science Today

http://www.plantsciencetoday.online

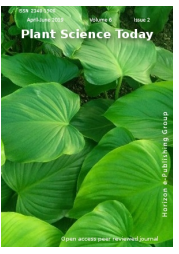

Research Article

\title{
Determination of antioxidant potential of biochemically synthesized silver nanoparticles using Aloe vera gel extract
}

\author{
Jasmeet Kaur Sohal $^{1}$, Ashish Saraf ${ }^{1}$, Kamlesh Kumar Shukla $^{2^{*}} \&$ Meghna Shrivastava $^{1}$ \\ ${ }^{1}$ Faculty of Biological and Chemical Sciences, MATS University, Raipur, Chhattisgarh, India \\ ${ }^{2}$ SoS Biotechnology, Pt. Ravishankar Shukla University, Raipur, Chhattisgarh, India
}

\section{Article history}

Received: 14 March 2019

Accepted: 20 April 2019

Published: 15 May 2019

\section{Publisher}

Horizon e-Publishing Group

\section{*Correspondence}

Kamlesh Kumar Shukla

曻hukla26@yahoo.co.in

\begin{abstract}
Biosynthesis of nanoparticles by using plant extracts is presently under development. The study has been focused on the biosynthesis of silver nanoparticles (AgNPs) using aqueous extract of Aloe vera gel as well as to determine their antioxidant potential. UV-Vis spectrophotometeric analysis showed surface plasmonic resonance (SPR) band at $440 \mathrm{~nm}$, which is specific for AgNPs. The Transmission Electron Microscopy (TEM) revealed that the synthesized AgNPs were spherical in shape with an average particle size of $66.6 \mathrm{~nm}$. Fourier Transform Infrared Spectroscopic (FTIR) analysis of the aqueous extract before and after the synthesis of AgNPs revealed the presence of different functional groups related to phenolic and polyphenolic compounds such as tannins and flavonoids, and other metabolites like proteins, which may be responsible for the synthesis and stabilization of AgNPs. The antioxidant potential of the synthesized AGAgNPs was determined by using 2, 2 Diphenyl-1- Picryl Hydrazyl (DPPH) radical scavenging, metal chelating and reducing power assay. Antioxidant assessment showed enhanced dose dependent antioxidant potential of the synthesized AgNPs as compared to the crude extract, which can gain attention of the pharmaceutical industry for preparation of antioxidants of natural origin as the synthetic ones are suspected to be carcinogenic. Present study also supports the advantages of green method for the nanoparticles synthesis.
\end{abstract}

Keywords: green synthesis, AgNPs, bioreduction, Aloe vera gel, characterization, antioxidant potential.

Citation: Sohal JK, Saraf A, Shukla KK, Shrivastava M. Determination of Antioxidant Potential of Biochemically Synthesized Silver Nanoparticles using Aloe vera gel Extract. Plant Science Today 2019;6(2):208-217. https://doi.org/10.14719/pst.2019.6.2.532

\begin{abstract}
Copyright: (c) Sohal et al (2019). This is an open-access article distributed under the terms of the Creative Commons Attribution License, which permits unrestricted use, distribution, and reproduction in any medium, provided the original author and source are credited (https://creativecommons.org/licenses/by/4.0/).
\end{abstract}

Indexing: Plant Science Today is covered by Scopus, CAS, AGRIS, CABI, Google Scholar, etc. Full list at http://www.plantsciencetoday.online

\section{Introduction}

Antioxidant can be defined as the substance that prevents or inhibits the accumulation of free radicals in the human body. Number of reactive oxygen species (ROS) and reactive nitrogen species (RNS) are generated in human body as byproducts of various types of metabolic activities, which are referred as free radicals, forming a large group of reactive organic species. Free radicals can be either neutral or ionic entities containing one or more unpaired electrons, produced continuously in human body and are also capable of independent existence. ROS and RNS include species such as hydroxyl radicals $\left(\mathrm{OH}^{-}\right)$, superoxide radical anion $\left(\mathrm{O}_{2}{ }^{-}\right)$, hydrogen peroxide $\left(\mathrm{H}_{2} \mathrm{O}_{2}\right)$, singlet oxygen species $\left({ }^{1} 0_{2}\right)$ and nitric oxide (NO) respectively (1). 

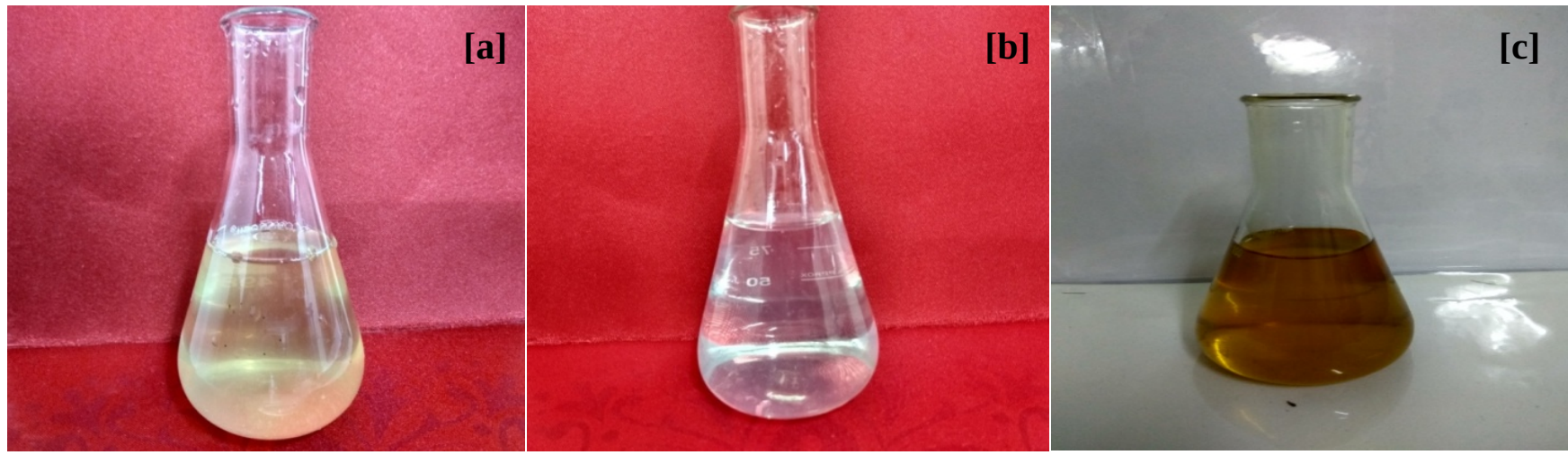

Fig. 2: (a) Aqueous extract of Aloe vera gel, (b) $1 \mathrm{mM} \mathrm{AgNO}_{3}$ solution and (c) AgNPs synthesized using aqueous extract of Aloe vera gel and $1 \mathrm{mM} \mathrm{AgNO}_{3}$ solution.

Elevated levels of ROS generate oxidative stress leading to various types detrimental effects, which includes enzyme activation/deactivation, lipid peroxidation of cellular membranes, DNA breakage, alterated lipid-protein interaction and eventually promoting mutations that initiate tumor progression $(2,3)$. If the balance between free radical generation and their eradication is maintained, the harmful effects caused by them in the body can be minimized.

Many of the human disorders like arthritis, atherosclerosis, ischemia, central nervous system injury, reperfusion injury of many tissues, diabetes, gastritis and cancer is caused due to oxidative damage by free radicals and reactive oxygen species $(4,5,6,7)$. To protect cellular molecules against the oxygen radical-induced damage the human body possesses multiple endogenous defense systems. These endogenous defense mechanisms include both enzymatic and non-enzymatic systems. The enzymatic defense system includes antioxidative enzymes like catalase (CAT), superoxide dismutase (SOD) and glutathione peroxidase (GSH-Px) (8). Against oxidative damage, these enzymes are our frontline defenders. Whereas the non-enzymatic defense system includes antioxidants like glutathione, vitamin $\mathrm{E}$ and $\mathrm{C}$ etc. which also protect the body from the oxidative stress induced damages. However, these innate defense systems are insufficient against severe oxidative stress, and overproduction of oxidative radicals may cause tissue damages.

A number of synthetic antioxidants like butylated hydroxytoluene (BHT), butylated hydroxyanisole (BHA), a-tocopherol, tertbutylhydroquinone (TBHQ) and trolox are extensively used in non-food industries, but their use in the food industries is prohibited because they are alleged to be extremely carcinogenic (9). As a result, the development and utilization of more efficient antioxidants of natural derivation are preferred (10).

To treat various diseases and conditions, plants have been used as a source of traditional medicine for many years. Various types of medicinal plants serve as outstanding source of phytochemicals with potent antioxidant properties (11).

In past few decades thorough investigation has been carried out for novel types of antioxidants from several plant materials $(12,13)$. Myriad of phenolic and polyphenolic compounds present in plants are found have effective antioxidant properties (14). These properties of medicinal plants when merged with nanoparticles can be beneficial for the medical science. Nanoparticles have different physical, chemical and biological properties from their bulk counterparts. They have high surface to volume ratio (15). Hence, higher antioxidant potential of nanoparticles as compared to the extract is anticipated due to the preferential adsorption of the antioxidant material onto the surface of the nanoparticles from the extract. Out of all the metallic nanoparticles silver nanoparticles grabs more attention due to its unique physical, chemical and biological properties.

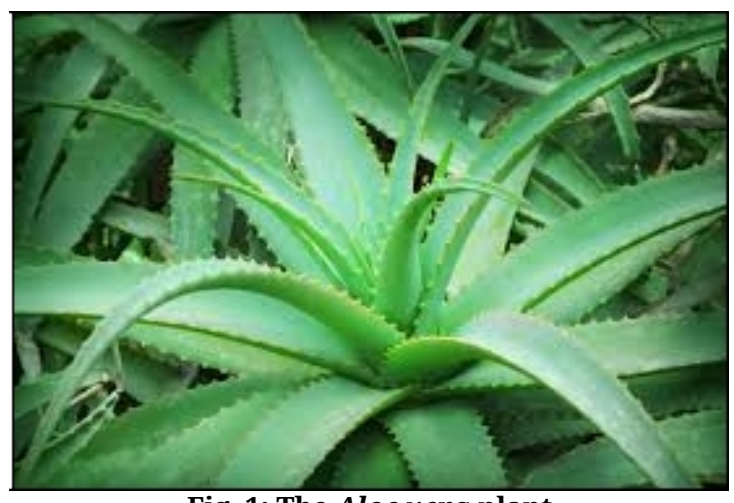

Fig. 1: The Aloe vera plant

Aloe vera is a unique plant which is a rich source of many chemical compounds and plays a significant role in the international market. From centuries the Aloe vera plant has been known and used for its health, beauty, medicinal and skin care properties. Aloe vera (Fig. 1) is perennial succulent belonging to the Lily (Liliaceae family) (16) and is granted with vast array of healing benefits. About 75 nutrients and 200 biologically active 
compounds including sugar, anthraquinones, saponins, vitamins, enzymes, minerals, lignin, salicylic acid and amino acids has been now reported as constituents of Aloe vera. Previous studies suggests that the organic extracts of Aloe vera gel possess potent in vivo and in vitro antioxidant potential (17,18). Though the information on the physiological properties and antioxidant potential of the Aloe vera gel are known, antioxidant properties of the AgNPs synthesized using it are not thoroughly worked. Present study has been carried out to assess the in vitro antioxidant potential of silver nanoparticles synthesized using aqueous extract of Aloe vera gel.

\section{Materials and Methods}

Collection of plant sample: The Aloe vera plant was collected from Centre of Excellence on MAPs (Medicinal and Aromatic Plants) and NTFP (Non Timber Forest Products), Indira Gandhi Krishi Vishwavidyalaya, Raipur, India $\left(21.2382^{\circ} \mathrm{N}\right.$, $81.7048^{\circ}$ E) and was identified by Dr. P.K. Joshi, Principal Scientist and Team Leader, Centre of Excellence on MAPs and NTFP, Indira Gandhi Krishi Vishwavidyalaya, Raipur, India.

Synthesis of silver nanoparticles: Silver nanoparticles in the present study were synthesized by standard published procedures with slight modifications.

- $\quad$ The fully expanded leaves of Aloe vera was selected from three years old plant, washed with distilled water and was subjected to surface sterilization with $70 \%$ ethyl alcohol followed by $0.1 \% \mathrm{HgCl}_{2}$.

- $\quad$ The parenchymatous covering of the leaves was peeled and the gel was drained out. Slurry was formed with the help of grinder.

- $\quad$ Aqueous extract of the gel was prepared by using methodology as described by Niko with slight modifications (19). $10 \mathrm{~g}$ of the gel formed was then mixed with $100 \mathrm{ml}$ of distilled water and kept in water bath at $60^{\circ} \mathrm{C}$ for 30 minutes.

- Using Whatman filter paper no. 1 the extract was then filtered and stored at $4^{\circ} \mathrm{C}$ for further use (Fig. 2a).

- One mM solution of silver nitrate (Molychem, M.W 169.87, 99.9\%, Thane, India) was formed by dissolving $17 \mathrm{mg} \mathrm{AgNO}_{3}$ in $100 \mathrm{ml}$ of distilled water (Fig. 2b).

- $\quad$ AGAgNPs (AgNPs synthesized using Aloe vera gel extract) were synthesized by addition of $10 \mathrm{ml}$ aqueous AGE (Aloe vera gel extract) to $40 \mathrm{ml}$ aqueous $1 \mathrm{mM}$ silver nitrate solution by constant stirring at $75^{\circ} \mathrm{C}$ for 40 minutes at neutral $\mathrm{pH}$ (Fig. 2c).

- The synthesized AGAgNPs were purified by centrifugation at $17000 \mathrm{rpm}$ for 20 minutes.
Purified AGAgNPs were used to determine in vitro antioxidant potential.

\section{Characterization of the synthesized AgNPs}

The bioreduction of silver ions by aqueous extract of Aloe vera gel was monitored by measuring the UV-visible spectrum of the reaction medium. UVvisible spectral analysis was done by using UVvisible spectrophotometer (Systronics, Double beam spectrophotometer, 2203) and the absorption maximum was scanned at the wavelength of 200-700 nm. The studies on size and morphology of AGAgNPs were performed by transmission electron microscopy. Transmission electron microscope (TEM) samples were prepared by placing a drop of dispersed AGAgNPs solution onto carboncoated copper grid. The micrographs were obtained on TECNAI G2 Spirit (FEI, Netherland) equipped with Gatan digital camera operated at an accelerating voltage at $80 \mathrm{kV}$. Fourier Transform Infrared Spectroscopic (FTIR) analysis of the aqueous extract before and after the synthesis of AgNPs was done to determine the presence of different functional groups responsible for the synthesis and stabilization of AgNPs.

\section{Total phenolic and flavonoid content measure}

Total phenolic content measure: Determination of total soluble phenolic compounds in the Aloe vera aqueous extract and the synthesized AGAgNPs was done by using Folin-Ciocalteau reagent following the methodology of Slinkard and Singleton (20). Gallic acid was used as standard. Briefly, $1 \mathrm{ml}$ of extract solution was diluted with 1 $\mathrm{ml}$ distilled water. $2 \mathrm{ml}$ of Sodium carbonate (2\%) followed by Folin-Ciocalteau reagent $(0.5 \mathrm{ml})$ was added, then the reaction mixture was allowed to stand for $2 \mathrm{hr}$ at $25^{\circ} \mathrm{C}$ with intermittent shaking. The absorbance was measured at $760 \mathrm{~nm}$. Total phenolic content in the aqueous extracts of AGE and AGAgNPs was measured by using calibration curve of gallic acid $\left(\mathrm{R}^{2}=0.99\right)$ and content was expressed as gallic acid equivalents (microgram of GAE).

Total flavonoid content measure: Determination of total flavonoid content in the aqueous AGE and AGAgNPs were determined by aluminum colorimetric method as described by Bibi et al., (21). The reaction mixture was prepared by adding $1 \mathrm{ml}$ of the sample to $10 \%$ aluminum chloride, $1 \mathrm{M}$ potassium acetate and distilled water. The reaction mixture was then incubated at room temperature for 30 mins and the absorbance was measured at $415 \mathrm{~nm}$. Flavonoid content in the aqueous extracts of AGE and AGAgNPs was measured by using calibration curve of quercetin $\left(\mathrm{R}^{2}=0.99\right)$ and content was expressed as quercetin equivalents (microgram of QE).

\section{Determination of antioxidant activity}

DPPH free radical scavenging assay: DPPH free radical scavenging activity of AGE and AGAgNPs 
was measured by using the method described by Blois (22). $0.1 \mathrm{mM}$ DPPH solution was prepared in methanol. $1 \mathrm{ml}$ of the solution was added to $3 \mathrm{ml}$ of aqueous extract of AG and AGAgNPs at different concentrations $(0.25,0.50,0.75$ and $1.00 \mathrm{mg} / \mathrm{ml})$. Mixture was shaken vigorously and allowed to stand at room temperature for $30 \mathrm{~min}$, and then absorbance was measured at $517 \mathrm{~nm}$ against blank sample, using UV-Vis spectrophotometer (Systronic). Standard antioxidant BHT was used as positive control and DPPH methanol reagent without sample was used as control. Higher the free radical scavenging activity, lower is the absorbance of the reaction mixture. Radical scavenging was expressed as the inhibition percentage and was calculated using the following formula (23):

$$
\% \text { of inhibition }=0 . D_{\text {control }} \text { O.D } D_{\text {test }} / O . D_{\text {control }}
$$

Where,

O. $\mathrm{D}_{\text {control }}=$ absorbance of the DPPH methanol reagent (without sample),

O. $\mathrm{D}_{\text {Test }}=$ absorbance of the test solution i.e AGE/AGAgNPs/Standard.

\section{Metal chelating activity}

Ferrozine quantitatively chelates with $\mathrm{Fe}^{2+}$ forming a red colored complex. In the presence of other chelating agents, the reaction gets limited which leads to the decrease in the color intensity of the ferrozine- $\mathrm{Fe}^{2+}$ complexes. The chelating activity of the aqueous extract of AG and AGAgNPs on $\mathrm{Fe}^{2+}$ was measured by the method of Decker and Welch (24). Aliquot of $1 \mathrm{ml}$ of different concentrations $(0.25,0.50,0.75$ and $1.00 \mathrm{mg} / \mathrm{ml})$ of the aqueous extract of AG and AGAgNPs were added to $2.5 \mathrm{ml}$ of distilled water. $\mathrm{FeCl}_{2}(2 \mathrm{mM}, 0.1 \mathrm{ml})$ and ferrozine $(5 \mathrm{mM}, 0.2 \mathrm{ml})$ were added to the reaction mixture and was left for 10 minutes at room temperature. The absorbance was then measured at $562 \mathrm{~nm}$. Higher chelating power is indicated by lowered absorbance. The chelating activity on $\mathrm{Fe}^{2+}$ of the test extracts were compared with that of EDTA. Chelating activity was calculated by using the following formula:

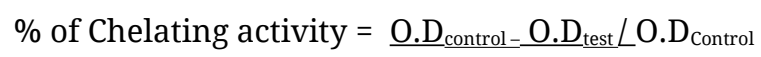

Where,

O. $\mathrm{D}_{\text {control }}=$ absorbance value of the solution without sample (control);

O. $\mathrm{D}_{\text {Test }}=$ absorbance of the test solution i.e AGE/AGAgNPs/Standard.

\section{Reducing power assay}

The reducing power of the aqueous extracts of AGE and AGAgNPs was measured by using the methodology of Oraiza (25). $0.5 \mathrm{ml}$ of each concentration $(0.25,0.50,0.75$ and $1.00 \mathrm{mg} / \mathrm{ml})$ was mixed with $2.5 \mathrm{ml}$ of phosphate buffer $(0.2 \mathrm{M}, \mathrm{pH}$ 6.6 ) and $2.5 \mathrm{ml}$ of potassium ferricyanide (1\%). The reaction mixture was then incubated for $20 \mathrm{~min}$ at $50^{\circ} \mathrm{C}$. In it, Trichloroacetic acid $(10 \%, 2.5 \mathrm{ml})$ was added. The mixture was centrifuged at $6000 \mathrm{rpm}$ for $10 \mathrm{~min}$ at $4^{\circ} \mathrm{C}$. The supernatant $(2.5 \mathrm{ml})$ was collected and $2.5 \mathrm{ml}$ of distilled water and $0.5 \mathrm{ml}$ ferric chloride $(0.1 \%)$ was added to it. Antioxidants present in the test samples would results in reduction of $\mathrm{Fe}^{3+} /$ Ferricyanide complex to the ferrous form $\left(\mathrm{Fe}^{2+}\right)$. The $\mathrm{Fe}^{2+}$ can, thus be monitored by measuring the formation of the Perl's Prussian blue color at $700 \mathrm{~nm}$ (26). The reducing power of the aqueous extract was compared with that of L-ascorbic acid as standard antioxidant. Increased absorbance values indicate a higher reducing power.

\section{Statistical analysis}

The statistical analysis was carried out by using $\mathrm{R}$. Mean and standard deviation of all the experiments was intended from triplicates $(n=3)$ and represented in the table (Mean \pm S.D) and figures (error bar). Variations within the experimental groups was determined by ANOVA.

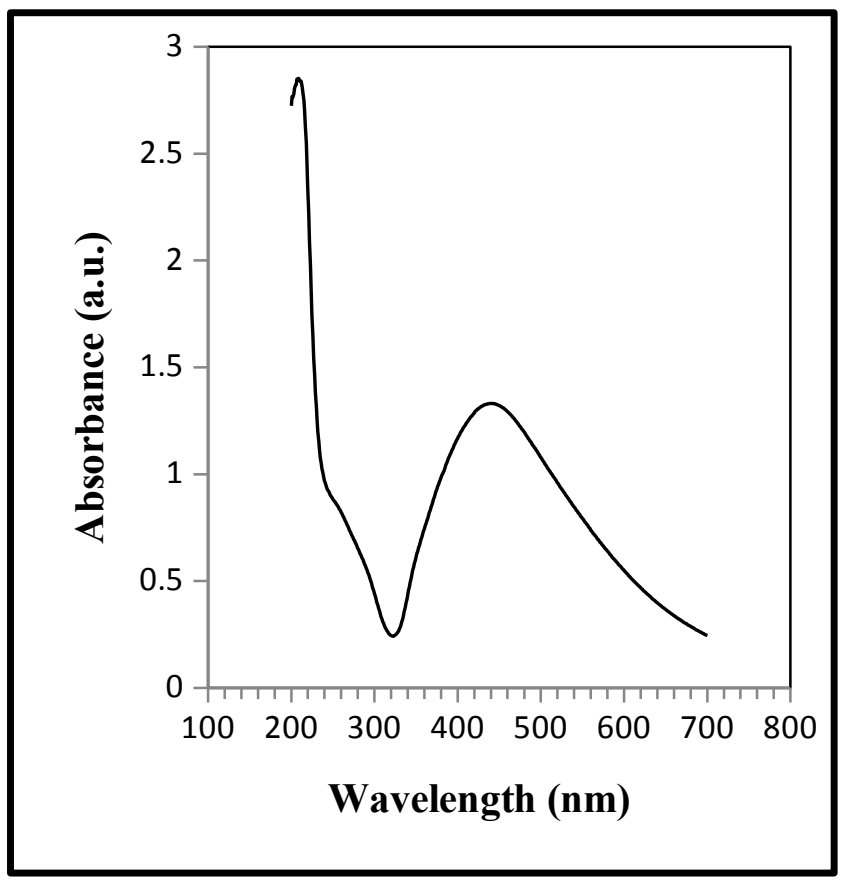

Fig. 3: UV-Vis Spectrum of AGAgNPs.

\section{Results and Discussion}

Characterization of the synthesized AGAgNPs: In present study the green synthesis of AgNPs using aqueous extract of Aloe vera gel has been elucidated. When the aqueous AGE was mixed with $1 \mathrm{mM} \mathrm{AgNO}{ }_{3}$ solution and incubated at $75^{\circ} \mathrm{C}$ for 40 minutes at neutral $\mathrm{pH}$, color changed to yellowish brown (Fig. 2c), which indicates the formation of AgNPs, this is preliminary identification of AgNPs formation. Color change in metal nanoparticles is due to the excitation of surface plasmon vibrations (27). Reaction medium containing AgNPs was subjected to UV-Vis spectral analysis where it showed sharp absorbance at 440 $\mathrm{nm}$ which is specific for AgNPs (Fig. 3). Two control reactions (Fig. 2a and 2b) were kept i.e. aqueous solution of $\mathrm{AgNO}_{3}$ which was without any 
Table 1: Total phenolic and flavonoid content determination in AGAgNPs and AGE. Values are presented as mean \pm SD from triplicate investigation.

\begin{tabular}{lll}
\hline Extract & TPC $\mu$ of GAE $/ \mathrm{mg}$ & TFC $\mu$ g of QE/mg \\
\hline AGE & $201.85 \pm 1.44$ & $46.04 \pm 0.57$ \\
\hline AGAgNPs & $146.85 \pm 1.44$ & $21.37 \pm 1.15$ \\
\hline
\end{tabular}

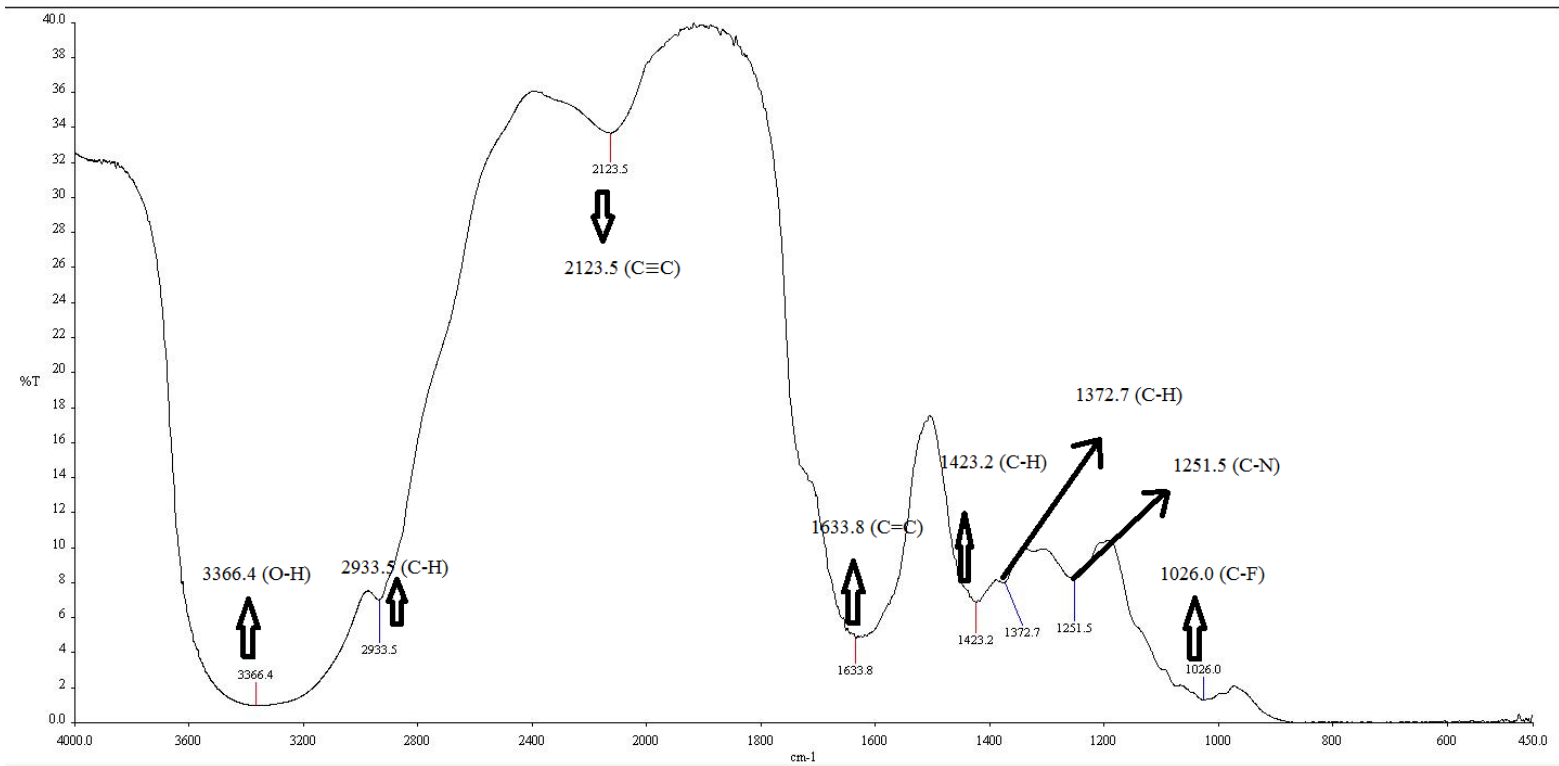

Fig. 5: FTIR Spectrum of AGE

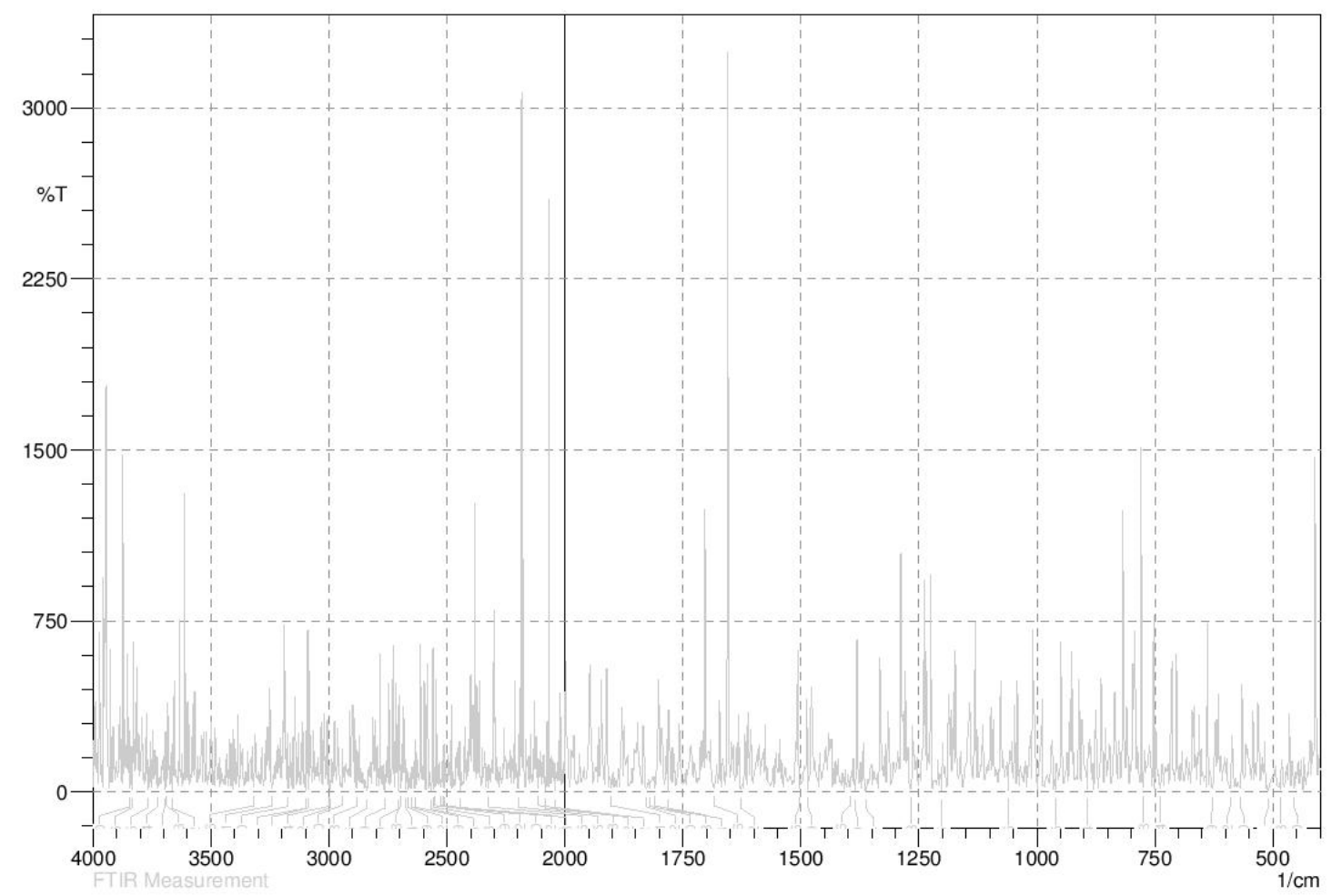

Fig. 6: FTIR Spectrum of AGAgNPs

colour and aqueous AGE that exhibit pale yellow colour. Reaction mixture containing silver nitrate solution and aqueous AGE showed yellowish brown colouration, which indicates the formation of AgNPs. Parallel control experiments didn't show any absorption at $440 \mathrm{~nm}$. TEM analysis provided details about the morphology and size of the synthesized AGAgNPs. The AGAgNPs formed was found to have an average size of $66.6 \mathrm{~nm}$ and spherical in shape and capped by plant constituents that prevented their aggregation. Silver nanoparticles of similar size were prepared by flower extract of Rhododendron dauricum (28). Natural capping offers supplementary advantage of the stability in the synthesis through green chemistry route as shown in Fig. 4. This stability is 


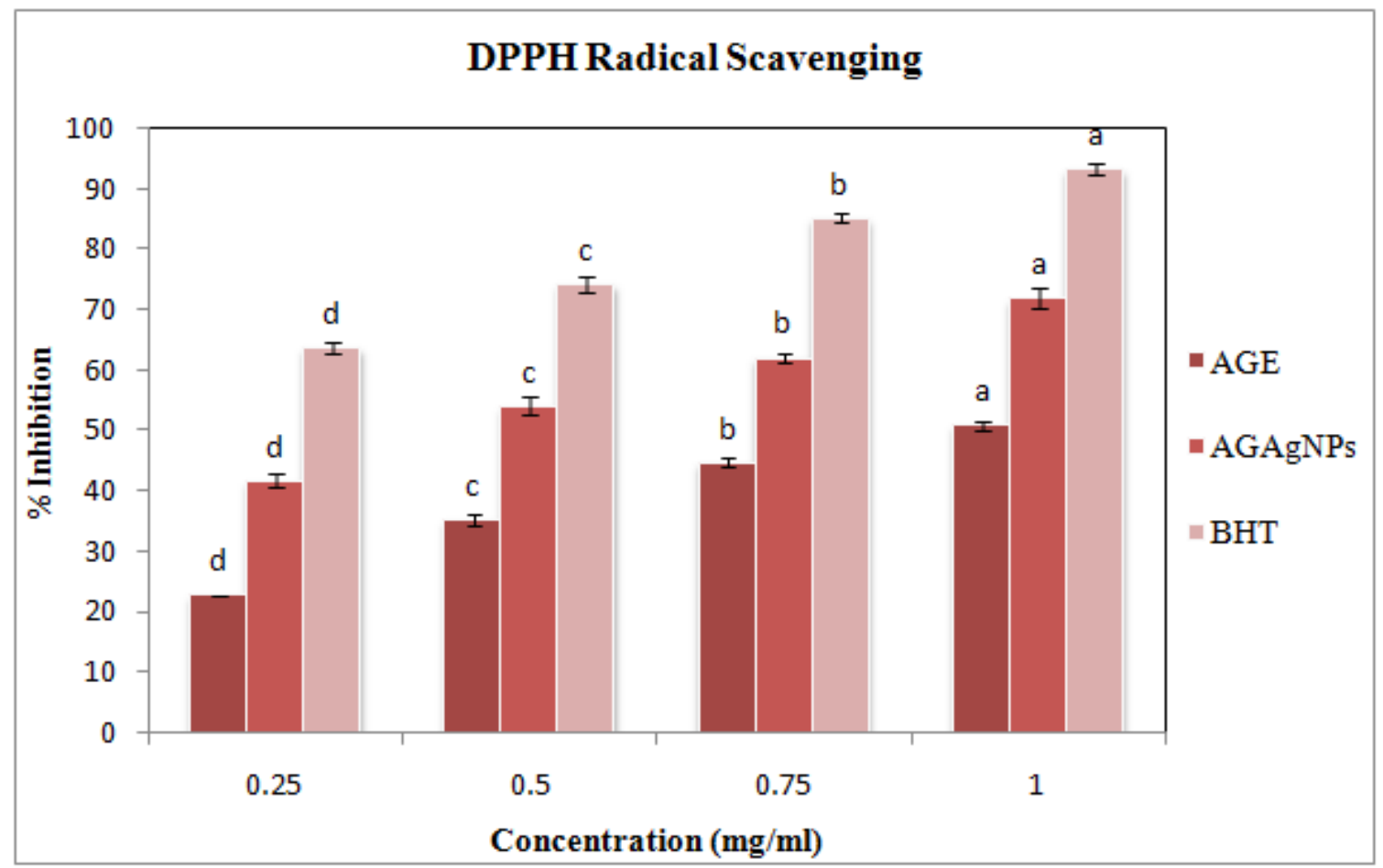

Fig. 7: DPPH free radical scavenging activity of AGE, AGAgNPs and BHT (Standard). Each bar represents Mean \pm S.D of three separate observations. The results were statistically significant at $\mathrm{p}<0.05$.

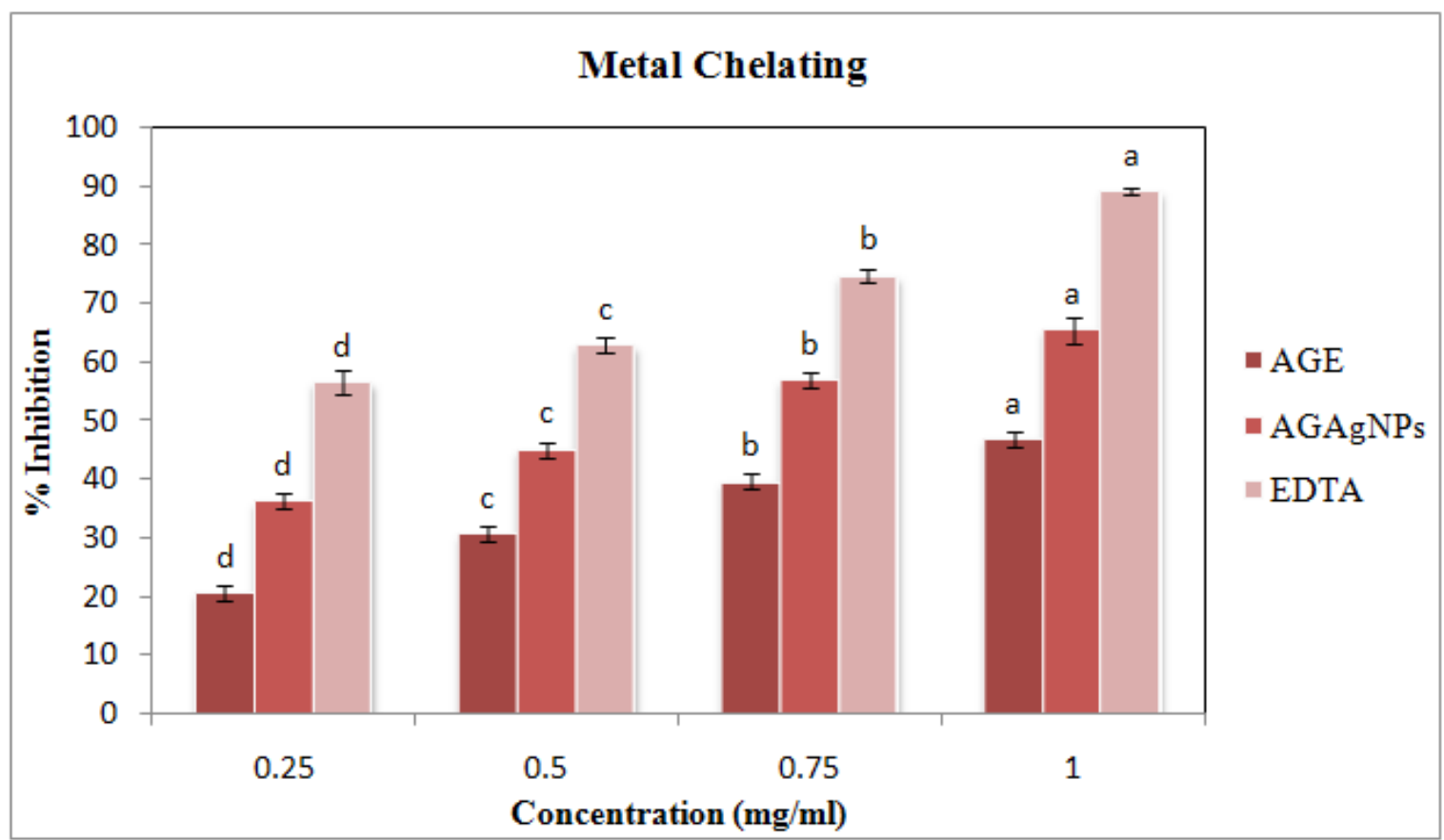

Fig. 8: Metal chelating activity of AGE, AGAgNPs and EDTA (Standard). Each bar represents Mean \pm S.D of three separate observations. The results were statistically significant at $\mathrm{p}<0.05$.

attributed to the phytoconstituents present in the exract, these results are in consensus with the reports by (29). The FTIR absorption spectra of the Aloe vera gel aqueous extract before and after the formation of AgNPs is shown in Fig. 5 and 6 respectively. Absorbance bands in Fig. 5 are observed in the region of $450-4000 \mathrm{~cm}^{-1}$ are 3366 , 2933, 2123, 1633, 1423, 1372, 1251 and $1026 \mathrm{~cm}^{-1}$. These absorbance bands of the FTIR spectrum are identified to be allied with the stretching vibrations for $\mathrm{O}-\mathrm{H}$ (hydrogen bonded alcohols and phenols), $\mathrm{C}-\mathrm{H}$ (Alkanes), $\mathrm{C} \equiv \mathrm{C}$ (Alkynes), $\mathrm{C}=\mathrm{C}$ (Alkenes), C-H (Alkanes), C-H (Alkanes), C-N (Amines, Amides) and C-F (Aliphatic fluoro compounds) respectively which proves the presence of phenolic and polyphenolic compounds such as flavonoids and tannins, and other metabolites like proteins (30) and disappearance of these band after bioreduction (Fig. 6) gives confirmation for the participation of these phytoconstituents in the formation and stabilization of AgNPs. 


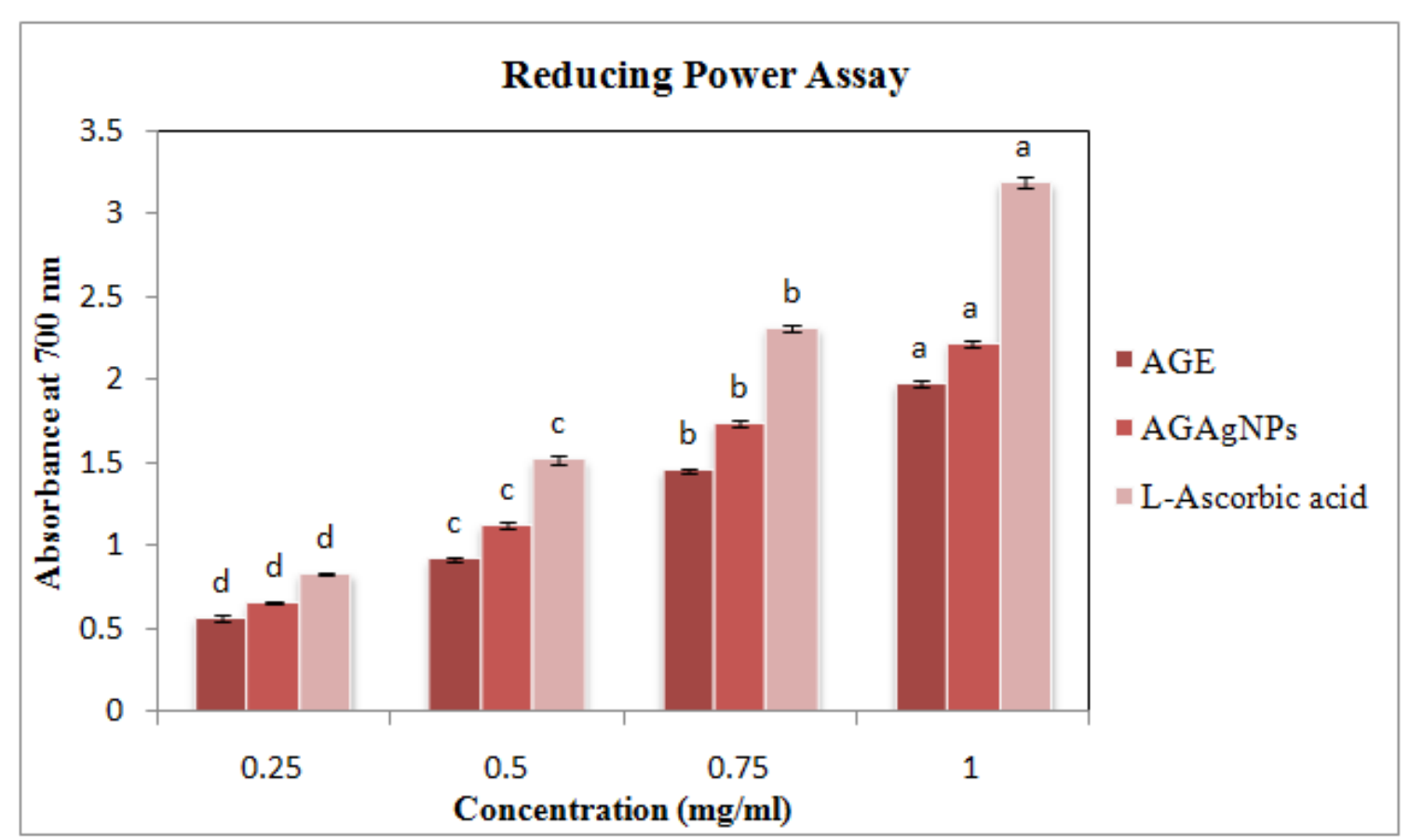

Fig. 9: Reducing of AGE, AGAgNPs and L-Ascorbic acid (Standard). Each bar represents Mean \pm S.D of three separate observations. The results were statistically significant at $\mathrm{p}<0.05$.

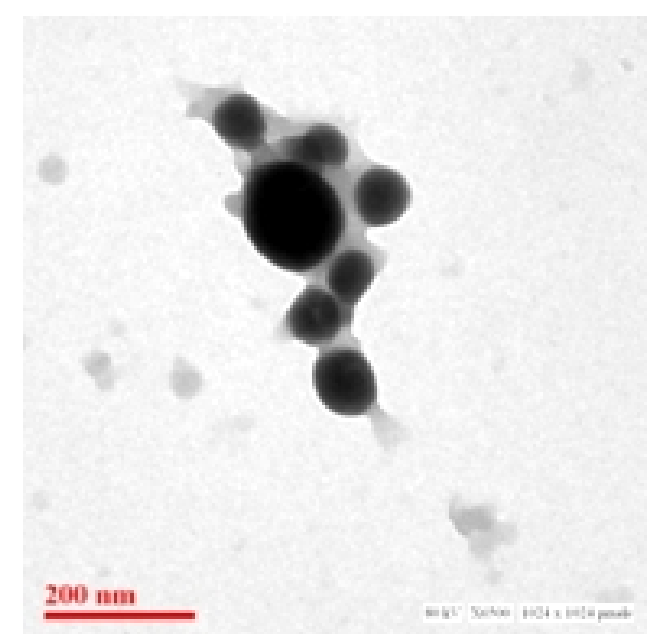

Fig. 4: TEM image for AGAgNPs

\section{Quantification of phenolic and flavonoid content}

Polyphenolic compounds derived from plants such as tannic acid has been reported to take part in the bioreduction of silver metal leading to the synthesis of nanoparticles (31). In order to confirm their role in the bioreduction process the total phenolic and flavonoid content in the crude extract and in the synthesized nanoparticles was measured.

Total phenol content: The linearity range of gallic acid was found for different concentrations $(15.625$ to $500 \mu \mathrm{g} / \mathrm{ml})$ with regression equation as $\mathrm{y}$ $=0.0040 \mathrm{x}+0.0159$ obtained from its calibration curve. The total phenolic content of synthesized AGAgNPs was found to be $146.85 \pm 1.44 \mu \mathrm{g}$ of $\mathrm{GAE} / \mathrm{mg}$ as compared to AG extract $(201.85 \pm 1.44 \mu \mathrm{g}$ of GAE/mg) phenol content (Table 1).
Total flavonoid content: The linearity range of quercetin was found for different concentrations $(12.25$ to $100 \mu \mathrm{g} / \mathrm{ml})$ with regression equation as $\mathrm{y}$ $=0.0100 \mathrm{x}+0.0129$ obtained from its calibration curve. The total flavonoid content of synthesized AGAgNPs was found to be $21.37 \pm 1.15 \mu \mathrm{g}$ of $\mathrm{QE} / \mathrm{mg}$ as compared to AG extract $(46.04 \pm 0.57 \mu \mathrm{g}$ of $\mathrm{QE} / \mathrm{mg}$ ) flavonoid content (Table 1).

Phenolics and flavonoids are nucleophilic in nature due to the presence of aromatic rings, hence, are responsible for having the chelating potential (31). Lowered amount of phenolic and flavonoid compounds measured in the synthesized AGAgNPs indicates their participation in the nanoparticles formation. Study carried out by Phull et al., reported decreased level of phenolic and flavonoid compounds in the silver nanoparticles synthesized using Bergenia ciliata rhizome compared to the extract support our results (32).

\section{In-vitro antioxidant activity}

DPPH free radical scavenging assay: The effect of antioxidants on DPPH is attributed to their hydrogen donating capacity (33). DPPH is a commercially available lipophilic radical, which can readily accept electron from the antioxidant compound and converting its color from purple to yellow which is detected at $517 \mathrm{~nm}$. The DPPH radical scavenging activity of AGE, AGAgNPs and standard (BHT) was studied using different concentration viz. $0.25,0.50,0.75$ and $1 \mathrm{mg} / \mathrm{ml}$. The $\%$ radical scavenging activity was found to increase in dose dependent manner in sequence BHT>AGAgNPs $>$ AGE (Fig. 7). Which shows that AGAgNPs contains potential antioxidant properties as compared to AGE, where BHT was used as standard. 


\section{Metal chelating activity}

In the metal chelating activity, Ferrozine quantitatively chelates with $\mathrm{Fe}^{2+}$ forming a red colored complex. In presence of other chelating agents, the reaction gets limited which leads to the decrease in the color intensity of the ferrozine- $\mathrm{Fe}^{2+}$ complexes. Chelating activity of the sample to compete with ferrozine for the ferrous ions can be estimated by the measurement of the color reduction (34). Metal chelating activity of AGE, AGAgNPs and standard (EDTA) on $\mathrm{Fe}^{2+}$ ions was studied the absorbance of Ferrozine- $\mathrm{Fe}^{2+}$ complex decreased linearly in a dose dependent manner $(0.25-1 \mathrm{mg} / \mathrm{ml})$. The Ferrozine-Fe ${ }^{2+}$ complex formation was disrupted by the presence of chelating agents in the sample. Thus, the decreased absorbance at $562 \mathrm{~nm}$ indicates high levels of iron binding potential. AGAgNPs showed higher chelating ability than that of AGE. However, it was relatively lower than that of EDTA. In this assay both the samples, AGE and AGAgNPs and standard EDTA compounds interfered with the formation of ferrous complex with the reagent ferrozine, suggesting that it has chelating activity and captures the ferrous ion before ferrozine. EDTA is a known metal ion chelator and is thus used for comparison. The result indicates that the sample has good iron binding capacity, suggesting its action as an antioxidant relating to its iron binding capacity (Fig. 8).

\section{Reducing power assay}

In the reducing power assay, the reduction of $\mathrm{Fe}^{3+}$ to $\mathrm{Fe}^{2+}$ has been attributed to the presence of reductants in the sample. Formation of Perl's blue at $700 \mathrm{~nm}$ indicates the amount of $\mathrm{Fe}^{2+}$ complex. Fig. 9 shows the reducing power of AGE and AGAgNPs and the reference compound, L-ascorbic acid. Here, the AGAgNPs showed more reducing power than that of AGE. However, it was relatively lower than that of L-ascorbic acid. A direct correlation between antioxidant activity and reducing power of certain plant extracts has been observed by earlier authors $(35,36)$. The reducing properties are generally associated with the presence of reductones (37) which have been shown to exert antioxidant action by breaking the free radical chain by donating hydrogen atom. The result suggests that samples are likely to contribute significantly towards the observed antioxidant effect, which increased in dose dependent manner $(0.25-1 \mathrm{mg} / \mathrm{ml})$.

Redox potential of phytoconstituents in the plant extract is responsible for its antioxidant activity (38), which could play an important role in satisfying singlet and triplet oxygen, decaying the peroxides or nullifying the free radicals. Nanoparticles have higher surface to volume ratio therefore, higher antioxidant potential of nanoparticles as compared to the extract is anticipated due to the preferential adsorption of the antioxidant material onto the surface of the nanoparticles from the extract.

Studies carried out by previous researchers reported enhanced antioxidant potential of the green synthesized nanoparticles as compared to the extract support our results $(39,40,41)$.

\section{Conclusion}

Present study reports the single step process for the biological synthesis of silver nanoparticles using aqueous extract of Aloe vera gel which comes up with ecofriendly, easy and proficient method for the synthesis of innocuous nanoparticles. The synthesized nanoparticles possessed the added advantage of active phytoconstituents incorporated in them. Moreover the synthesized silver nanoparticles exhibited an enhanced antioxidant potential then the crude extract, which illustrate the application of bioactive silver nanoparticles as an excellent antioxidant agent of natural origin.

\section{Acknowledgement}

The authors express their gratitude to the Head, MATS school of Biological and Chemical Sciences, MATS University, for providing central laboratory facilities.

\section{Competing Interests}

The authors declare that they have no competing interest.

\section{Author's Contribution}

AS and KKS designed the objectives and plan of work. JKS carried out the work. JKS and MS wrote the manuscript.

\section{References}

1. Fang YZ, Yang S, Wu G. Free radicals, antioxidants, and nutrition. Nutrition 2002;18(10):872-9. https://doi.org/10.1016/S0899 9007(02)00916-4

2. Agarwal A, Saleh RA, Bedaiwy MA. Role of reactive oxygen species in the pathophysiology of human reproduction. Fertility and sterility. 2003;79(4):82943. https://doi.org/10.1016/S0015-0282(02)04948-8

3. Lefebvre PP, Malgrange B, Lallemend F, Staecker H, Moonen G, Van De Water TR. Mechanisms of cell death in the injured auditory system: otoprotective strategies. Audiology and Neurotology. 2002;7(3):165-70. https://doi.org/10.1159/000058304

4. Pourmorad F, Hosseinimehr SJ, Shahabimajd N. Antioxidant activity, phenol and flavonoid contents of some selected Iranian medicinal plants. African journal of biotechnology 2006;5(11). 
5. Wong SP, Leong LP, Koh JH. Antioxidant activities of aqueous extracts of selected plants. Food chemistry 2006;99(4):775-83.

https://doi.org/10.1016/j.foodchem.2005.07.058

6. Su L, Yin JJ, Charles D, Zhou K, Moore J, Yu LL. Total phenolic contents, chelating capacities, and radicalscavenging properties of black peppercorn, nutmeg, rosehip, cinnamon and oregano leaf. Food chemistry. 2007;100(3):990-7. https://doi.org/10.1016/ j.foodchem.2005.10.058

7. Tepe B, Eminagaoglu O, Akpulat HA, Aydin E. Antioxidant potentials and rosmarinic acid levels of the methanolic extracts of Salvia verticillata (L.) subsp. verticillata and $S$. verticillata (L.) subsp. amasiaca (Freyn \& Bornm.) Bornm. Food Chemistry 2007;100(3):985-9.

https://doi.org/10.1016/j.foodchem.2005.10.062

8. Lassen N, Black WJ, Estey T, Vasiliou V. The role of corneal crystallins in the cellular defense mechanisms against oxidative stress. In: Seminars in cell \& developmental biology 2008;19:100-112). Academic https://doi.org/10.1016/j.semcdb.2007.10.004

9. Valentão P, Fernandes E, Carvalho F, Andrade PB, Seabra RM, Bastos ML. Antioxidative properties of cardoon (Cynara cardunculus L.) infusion against superoxide radical, hydroxyl radical, and hypochlorous acid. Journal of agricultural and food chemistry https://doi.org/10.1021/jf0202250

10. Gülçin İ, Oktay M, Küfrevioğlu Öİ, Aslan A. Determination of antioxidant activity of lichen Cetraria islandica (L) Ach. Journal of Ethnopharmacology 2002;79(3):325-9. https://doi.org/10.1016/S03788741(01)00396-8

11. Singh P, Yadav RJ, Pandey A. Utilization of indigenous systems of medicine \& homoeopathy in India. Indian Journal of Medical Research 2005;122(2):137.

12. Kochhar KP. Dietary spices in health and diseases: I. Indian J Physiol Pharmacol. 2008;52(2):106-22.

13. Saxena R, Venkaiah K, Anitha P, Venu L, Raghunath M. Antioxidant activity of commonly consumed plant foods of India: contribution of their phenolic content. International Journal of Food Sciences and Nutrition 2007;58(4):250-60.

14. Ramkumar KM, Manjula C, Sankar L, Suriyanarayanan S, Rajaguru P. Potential in vitro antioxidant and protective effects of Gymnema montanum $\mathrm{H}$. on alloxan-induced oxidative damage in pancreatic $\beta$-cells, HIT-T15. Food and chemical toxicology https://doi.org/10.1016/j.fct.2009.06.011

15. Saqib S, Hussain Munis MF, Zaman W, Ullah F, Shah SN, Ayaz A, Farooq M, Bahadur S. Synthesis, characterization and use of iron oxide nano particles for antibacterial activity. Microscopy research and technique. 2018;82:415-420. https://doi.org/10.1002/jemt.23182

16. Skousen MV. The ancient egyptian medicine plant: Aloe vera. Cypress (California): Aloe vera Research Inst. 1979;20.
17. Anilakumar KR, Sudarshanakrishna KR, Chandramohan G, Ilaiyaraja N, Khanum F, Bawa AS. Effect of Aloe vera gel extract on antioxidant enzymes and azoxymethane-induced oxidative stress in rats. Indian J Exp Biol. 2010;48(8):837-42.

18. Saritha V, Anilakumar KR, Khanum F. Antioxidant and antibacterial activity of Aloe vera gel extracts. International Jurnal of Pharmaceutical \& Biological Archives 2010;1(4):376-84.

19. Niko N. Inhibitory effects of Aloe vera gel aqueous extract and $L$. casei against $E$. coli in yoghurt. Journal of Biology and Today's World 2016;5(9):15762. https://doi.org/10.15412/J.JBTW.01050901

20. Slinkard K, Singleton VL. Total phenol analysis: automation and comparison with manual methods. American journal of enology and viticulture 1977;1:28(1):49-55.

21. Bibi G, Ullah N, Muazzam AG, Mannan A, Mirza B. Phytochemical evaluation of naturally growing Aster thomsonii plant species. J Pharm Harb Form. 2012;2:33-9.

22. Blois MS. Antioxidant determinations by the use of a stable free radical. Nature 1958;181(4617):1199.

23. Yen GC, Duh PD. Scavenging effect of methanolic extracts of peanut hulls on free-radical and activeoxygen species. Journal of Agricultural and Food Chemistry 1994;42(3):629-32. https://doi.org/10.1021/ jf00039a005

24. Decker EA, Welch B. Role of ferritin as a lipid oxidation catalyst in muscle food. Journal of Agricultural and food Chemistry 1990;38(3):674-7. https://doi.org/10.1021/jf00093a019

25. Oraiza M. Studies on product of browning reaction prepared from glucosamine. Japanese Journal of Nutrition 1986;44:307-15.

26. Chung YC, Chang CT, Chao WW, Lin CF, Chou ST. Antioxidative activity and safety of the 50 ethanolic extract from red bean fermented by Bacillus subtilis IMR-NK1. Journal of Agricultural and Food Chemistry 2002;50(8):2454-8. https://doi.org/10.1021/ j011369q

27. Ahmad A, Mukherjee P, Senapati S, Mandal D, Khan MI, Kumar R, Sastry M. Extracellular biosynthesis of silver nanoparticles using the fungus Fusarium oxysporum. Colloids and surfaces B: Biointerfaces 2003;28(4):313-8.

https://doi.org/10.1016/S09277765(02)00174-1

28. Mittal AK, Kaler A, Banerjee UC. Free Radical Scavenging and Antioxidant Activity of Silver Nanoparticles Synthesized from Flower Extract of Rhododendron dauricum. Nano Biomedicine \& Engineering 2012;4(3).

29. Ahmad N, Sharma S, Alam MK, Singh VN, Shamsi SF, Mehta BR, Fatma A. Rapid synthesis of silver nanoparticles using dried medicinal plant of basil. Colloids and Surfaces B: Biointerfaces 2010;81(1):816. https://doi.org/10.1016/j.colsurfb.2010.06.029

30. Interpretation of infrared spectra. Slideshare. https://www.slideshare.net/aksharanaidu967/keerth i-ppt (Accessed 2018-11-18)

31. Sivaraman SK, Elango I, Kumar S, Santhanam V. A green protocol for room temperature synthesis of 
silver nanoparticles in seconds. Current Science 2009;97(7):1055-9.

32. Phull AR, Abbas Q, Ali A, Raza H, Zia M, Haq IU. Antioxidant, cytotoxic and antimicrobial activities of green synthesized silver nanoparticles from crude extract of Bergenia ciliata. Future Journal of Pharmaceutical Sciences 2016;2(1):31-6. https://doi.org/10.1016/j.fjps.2016.03.001

33. Baumann J. Prostaglandin synthetase inhibiting O_2-radical scavenging properties of some flavonoids and related phenolic compounds. Naunyn-Schmiedebergs Arch Pharmacol. 1979;308:27-32.

34. Soler-Rivas C, Espín JC, Wichers HJ. An easy and fast test to compare total free radical scavenger capacity of foodstuffs. Phytochemical Analysis: An International Journal of Plant Chemical and Biochemical Techniques 2000;11(5):330-8. https://doi.org/10.1002/10991565(200009/10)11:5\%3C330::aid-pca534\%3E3.3.co;2-7

35. Tanaka M, Kuie CW, Nagashima YAA, Taguchi T. Application of antioxidative Maillard reaction products from histidine and glucose to sardine products. Nippon Suisan Gakkaishi, 1988;54(8):14091414. https://doi.org/10.2331/suisan.54.1409

36. Meir S, Kanner J, Akiri B, Philosoph-Hadas S. Determination and involvement of aqueous reducing compounds in oxidative defense systems of various senescing leaves. Journal of agricultural and food chemistry 1995;43(7):1813-9. https://doi.org/10.1021/jf00055a012

37. Duh PD. Antioxidant activity of burdock (Arctium lappa Linné): Its scavenging effect on free-radical and active oxygen. Journal of the American Oil Chemists' Society 1998;75(4):455-61. https://doi.org/10.1007/s11746-998-0248-8

38. Zheng W, Wang SY. Antioxidant activity and phenolic compounds in selected herbs. Journal of agricultural and food chemistry 2001;49(11):516570. https://doi.org/10.1021/jf010697n

39. Bhakya S, Muthukrishnan S, Sukumaran M, Muthukumar M. Biogenic synthesis of silver nanoparticles and their antioxidant and antibacterial activity. Applied Nanoscience 2016;;6(5):755-66.

40. Patil Shriniwas P. Antioxidant, antibacterial and cytotoxic potential of silver nanoparticles synthesized using terpenes rich extract of Lantana camara L. leaves. Biochemistry and biophysics reports 2017;10:76. https://doi.org/10.1016/j.bbrep.2017.03.002

41. Otunola GA, Afolayan AJ. In vitro antibacterial, antioxidant and toxicity profile of silver nanoparticles green-synthesized and characterized from aqueous extract of a spice blend formulation. Biotechnology \& Biotechnological Equipment 2018;32(3):724-33. 